\title{
A Modified Harmony Search Algorithm for the Economic Dispatch Problem
}

\author{
Dinu Călin SECUI, Gabriel BENDEA, Simona DZIŢAC, Codruţa BENDEA, Cristina HORA \\ University of Oradea, University Street, Oradea, 410087, Romania \\ csecui@uoradea.ro,gbendea@uoradea.ro,simona.dzitac@gmail.com,cbendea@uoradea.ro, \\ chora@uoradea.ro
}

\begin{abstract}
The paper presents a modified harmony search algorithm (MHS), useful for solving the economic dispatch (ED) problem assuming a non-linear cost function and various technical restrictions. The ED problem is a very important optimization problem for power systems, and technical restrictions must be considered: prohibited operating zones and ramp rate limits of power generating units, as well as transmission line losses. The MHS algorithm is based on harmony search (HS) algorithm, but a new harmony is obtained by inserting some features from artificial bee colony algorithm. The efficiency of MHS algorithm is tested against two systems consisting of 6 and 38 thermal power generating units. Results are compared with those obtained by applying other optimization techniques.
\end{abstract}

Keywords: economic dispatch; harmony search; transmission losses.

\section{Introduction}

Economic dispatch (ED) is an optimization problem of power systems that aims to determine the output power of thermal power generating units in order to have a minimal fuel cost for the entire system and, in the mean time, to satisfy some technical restrictions while operating the units.

The mathematical model of ED problem is nonlinear, where both objective function and restrictions system may be non-linear. Classical methods were used for solving the ED problem: linear programming [1], non-linear programming [2], quadratic programming [3], Lagrangian relaxation algorithm [4] and dynamic programming [5]. Usually, these methods have got difficulties in finding a global optimum, they being able to offer only a local optimum point. Moreover, classical methods need a calculation of derivatives and some checking on continuity and derivability conditions of functions belonging to optimization model. To cover these drawbacks several artificial intelligence-based optimization techniques were applied. One of the most frequently used methods is based on the particle swarm optimization (PSO) applied in classical, enhanced or hybrid versions: PSO, PSO with time varying acceleration coefficients (PSO-TVAC) [6-8], new PSO (NPSO, NPSOLSR) [9, 10], improved PSO [11], distributed Sobol PSO with tabu search algorithm (DSPSO-TSA) [12]. Other methods used for solving ED problems are: evolutionary programming (EPs) [13], biogeography-based optimization (BBO) [14], tabu search and multiple tabu search (TS, MTS) [15], differential evolution (DE) [16, 17], hybrid DE (DEPSO) [18], artificial bee colony algorithm (ABC) [19], incremental ABC with local search (IABC-LS) [20], harmony search (HS) [21], differential HS (DHS) [22].

Harmony search is a meta-heuristic algorithm inspired from a musical process of searching for a perfect state of harmony. The HS is an easy to implement algorithm, having good convergence characteristics and may be easily adapt to work with other algorithms [23, 24]. Thus, the HS algorithm or its versions were successfully used for solving mathematical [2527] and engineering problems with continuous variables: reliability optimization [28], automatic parameter configuration [29], design of water distribution networks [30] etc.

In this paper, the HS classical algorithm is enhanced with some features specific to artificial bee colony algorithm in order to solve the economic dispatch problem. The new algorithm is called modified harmony search (MHS) algorithm. Its results are compared with others obtained by applying different optimization techniques.

\section{ED Problem Formulation}

Considering a power system where $\boldsymbol{n}$ thermal generating power units are operating, each unit having an output power $P_{i}, i=1,2, \ldots, n$. Output powers $P_{i}$ define the solution vector $P=\left[P_{1}, P_{2}, \ldots, P_{i}, \ldots, P_{n}\right]^{\mathrm{T}}$. The fuel cost $F_{i}\left(P_{i}\right)$, 
for each generator $i$, may be represented by a quadratic polynomial function such as:

$$
F_{i}\left(P_{i}\right)=c_{i} P_{i}^{2}+b_{i} P_{i}+a_{i}
$$

where $a_{i}, b_{i}$ and $c_{i}$ are fuel cost coefficients of generator $i$.

To solve an ED problem means determining the $P_{i}$ output powers of the generating units, so that the total fuel cost (objective function) is minimal, considering a set of equality and inequality technical constraints. The objective function is:

$$
\min F=\sum_{i=1}^{n} F_{i}\left(P_{i}\right)
$$

The equality and inequality constraints for the ED problem are given by (3)-(8) relations:

i) Minimum and maximum real power operating limits:

$\mathrm{P}_{\mathrm{i}, \min } \leq \mathrm{P}_{\mathrm{i}} \leq \mathrm{P}_{\mathrm{i}, \max }, \mathrm{i}=1,2, \ldots, \mathrm{n}$

where $P_{i, \min }$ and $P_{i, \max }$ represent the minimum and the maximum operating limits of a generator $i$.

ii) Generator ramp-rate limits:

$$
P_{i} \leq P_{i}{ }^{P r e v}+U R_{i} \text {, if output power increases }
$$

$P_{i} \geq P_{i}^{P r e v}-D R_{i}$, if output power decreases

where $P_{i}^{\text {Prev }}$ is the previous hour output power of unit $i . D R_{i}$ and $U R_{i}$ are the down-ramp and up-ramp limits of the $i$ unit.

Relations (3)-(5) can also be expressed by:

$\mathrm{PO}_{\mathrm{i}, \min } \leq \mathrm{P}_{\mathrm{i}} \leq \mathrm{PO}_{\mathrm{i}, \max }$

where $P O_{i, \min }=\max \left(P_{i, \text { min }}, P_{i}^{\text {Prev }}-D R_{i}\right)$ and $P O_{i, \max }=\min \left(P_{i, \max }, P_{i}^{\text {Prev }}+U R_{i}\right)$.

iii) Prohibited operating zones of the generator. Power generating units may have some prohibited operating zones, which, for a certain $i$ generator, are given by:

$\mathrm{P}^{\mathrm{L}, \mathrm{z}}<\mathrm{P}_{\mathrm{i}}<\mathrm{P}_{\mathrm{i}, \mathrm{z}}^{\mathrm{U}}, \quad \mathrm{Z}=1,2, \ldots, \mathrm{NZ}_{\mathrm{i}}$

where $N Z_{i}$ is the number of prohibited zones of unit $i . P_{i, z}^{L}$ and $P_{i, z}^{U}$ are the lower and upper boundary of the $z$ prohibited operating zone for the unit $i$.

iv) Real power balance constraint:

$$
P_{G}-P_{L}-P_{D}=0
$$

where $P_{D}$ is the load demand in the system, in MW. $P_{L}$ represents the transmission loss, in MW.
The transmission losses $P_{L}$ at the entire system level are calculated using constant $B$ coefficient formula (Kron's relation):

$P_{L}=\sum_{i=1}^{n} \sum_{j=1}^{n} P_{i} B_{i j} P_{j}+\sum_{i=1}^{n} B_{0 i} P_{i}+B_{00}$

where $B_{i j}$ is an element of the loss coefficient matrix of size $n \times n, B_{0 i}$ is $i$ element of the loss coefficient vector of size $n$ and $B_{00}$ is the loss coefficient constant.

The total generated power $\left(P_{G}\right)$ of the system by the $n$ units is:

$$
P_{G}=\sum_{i=1}^{n} P_{i}
$$

\section{The Harmony Search Algorithm}

Harmony search (HS) is a meta-heuristic population-based algorithm inspired from the musical process of searching for a perfect state of harmony. It was proposed by Geem et al. [23] and developed by Lee and Geem [24] for engineering optimization problems with continuous variables.

Generally, HS algorithm is used to solve optimization problems with continuous parameter. Thus, the optimization problem consists of searching the minimum of an $f(x)$ function considering the constraints $\mathrm{x}_{\mathrm{i}}{ }^{\text {min }} \leq \mathrm{x}_{\mathrm{i}} \leq \mathrm{x}_{\mathrm{i}}{ }^{\max }, i=1,2, \ldots, n$, where $n$ is the number of decision variables, and $x_{i}^{\min }$ and $x_{i}^{\max }$ are lower and upper limits for the variable $\mathrm{x}_{\mathrm{i}}$. Function $f(\boldsymbol{x})$ represents the objective function, $\boldsymbol{x}=\left(\mathrm{x}_{1}, \mathrm{x}_{2}, . ., \mathrm{x}_{\mathrm{n}}\right)$ is the $n$-dimensional solution vector, and $\mathrm{x}_{\mathrm{i}}$ is the $i^{\text {th }}$ component of $\boldsymbol{x}$ vector.

The HS algorithm is defined by the following parameters [24]: the harmony memory size (HMS), harmony memory considering rate (HMCR), pitch adjusting rate (PAR), distance bandwidth (bw) and maximum number of iterations (improvisations) $\left(\mathrm{N}_{\max }\right)$. HMS is the number of vectors in harmony memory that satisfy the constraints of the problem, and HMCR and PAR are the parameters used for generating a new vector.

During the optimization process, solution vectors are being stored as a harmony memory $\mathrm{HM}=\left[\boldsymbol{x}_{1}, \boldsymbol{x}_{2}, . ., \boldsymbol{x}_{\mathrm{HMS}}\right]$. Each vector $\boldsymbol{x}_{j \mid j=1,2, . . H M S}$, belonging to $\mathrm{HM}$ is a possible solution of the problem. The optimization procedure that uses 
HS meta-heuristic algorithm consists of the following steps $[23,24]$ :

Step 1. Initialize the optimization problem and algorithm parameters. Here, the parameters of HS algorithm are initialized: HMS, HMCR, PAR, bw and $\mathrm{N}_{\max }$. Also, lower $\left(\mathrm{x}_{\mathrm{i}}^{\mathrm{min}}\right)$ and upper $\left(\mathrm{x}_{\mathrm{i}}^{\max }\right)$ limits for the variable $\mathrm{x}_{\mathrm{i}}$ are set, as well as other specific parameters of the problem.

Step 2. Initialize the harmony memory (HM). Initially, HM matrix consists of HMS harmonies (column solution vectors). The elements of each vector $\left.\boldsymbol{x}_{j}\right|_{j=1,2, . . H M S,}$ are randomly generated, inside $\left[\mathrm{x}_{\mathrm{i}}^{\min }, \mathrm{x}_{\mathrm{i}}^{\max }\right]_{i=1,2, . \mathrm{n} \text {, }}$ interval having a uniform distribution:

$\mathrm{x}_{\mathrm{i}}=\mathrm{x}_{\mathrm{i}}{ }^{\min }+\operatorname{rand}() \times\left(\mathrm{x}_{\mathrm{i}}^{\max }-\mathrm{x}_{\mathrm{i}}^{\min }\right), i=1,2, . ., n$

$\operatorname{rand}()$ is a uniformly distributed number inside $[0,1]$ interval.

Then, for each HM vector $\left(\boldsymbol{x}_{j} \mid j=1,2, . . H M S\right)$ the value of the objective function $f\left(\boldsymbol{x}_{\mathrm{j}}\right)$ is determined.

Step 3. Improvise a new harmony. The new harmony vector, $\boldsymbol{x}^{\text {new }}=\left(\mathrm{x}_{1}{ }^{\text {new }}, \mathrm{x}_{2}{ }^{\text {new }}, \ldots, \mathrm{x}_{\mathrm{n}}{ }^{\text {new }}\right)$ is generated from the HM by sequentially applying three rules: memory considerations, pitch adjustments, and random selection. Each element $\left(\left.\mathrm{x}_{\mathrm{i}}^{\text {new }}\right|_{i=1,2, . n}\right)$ belonging to vector $\boldsymbol{x}^{\text {new }}$ is generated using the following procedure [24, 27]:

If $\operatorname{rand}() \leq \mathrm{HMCR}$ then begin /memory consideration/

$\mathrm{x}_{\mathrm{i}}{ }^{\text {new }}=\mathrm{x}_{\mathrm{ij}}$, unde $j \sim \mathrm{U}[1, \mathrm{HMS}]$ and $i=1,2, . ., n$

If rand ()$\leq$ PAR then /pitch adjustment/

$\mathrm{x}_{\mathrm{i}}{ }^{\text {new }}=\mathrm{x}_{\mathrm{i}}{ }^{\text {new }} \pm r \times \mathrm{bw}$, unde $r \sim \mathrm{U}[0,1]$ end

else /random selection/

$\mathrm{x}_{\mathrm{i}}=\mathrm{x}_{\mathrm{i}}{ }^{\min }+\operatorname{rand}() \times\left(\mathrm{x}_{\mathrm{i}}{ }^{\text {max }}-\mathrm{x}_{\mathrm{i}}{ }^{\min }\right), i=1,2, . ., n$

$r$ and $\operatorname{rand}()$ are uniformly distributed random numbers in the range $[0,1]$.

Step 4. Update the harmony memory. If the new harmony vector $\boldsymbol{x}^{\text {new }}$ is better than the worst harmony vector ( $x^{\text {worst }}$ ) of HM, then $\boldsymbol{x}^{\text {worst }}=\boldsymbol{x}^{\text {new }}$. The objective function $f(\boldsymbol{x})$ is used for comparing $\boldsymbol{x}^{\text {new }}$ and $\boldsymbol{x}^{\text {worst }}$ vectors.

Step 5. Check the stopping criterion. The algorithm stops when then maximum number of iterations $\left(N_{\max }\right)$ is reached. If $k<N_{\max }$ then go to Step 3 ( $k$ current number of the iteration), otherwise Stop and return the best harmony (solution) din HM.

\section{The modified harmony search (MHS) algorithm}

The MHS algorithm is built on the same steps like HS algorithm, its purpose being the enhancement of classical HS algorithm performances. The difference between MHS algorithm and HS algorithm is made by the generating way of the new harmony described at step 3. The following changes have been done to MHS algorithm:

- the rule regarding the "random selection" of a new harmony vector is eliminated;

- equation (12) regarding "memory consideration" is replaced with equation (15) that borrows from artificial bee colony algorithm some features for generating the solution $[31,32]$ :

$$
\begin{aligned}
& \mathrm{x}_{\mathrm{i}}^{\text {new }}=\mathrm{x}_{\mathrm{ij}}+\mathrm{U}(-1,1) \times\left(\mathrm{x}_{\mathrm{ij}}-\mathrm{x}_{\mathrm{ik}}\right), \quad j \sim \mathrm{U}[1, \mathrm{HMS}], \\
& k \sim \mathrm{U}[1, \mathrm{HMS}], j \neq k \text { and } i=1,2, \ldots, n
\end{aligned}
$$

- equation (13) regarding "pitch adjustment" is replaced with equation (16). This searching strategy is based on the advantages offered by the best global solution and is similar with the one in $\mathrm{ABC}$ algorithm [20]:

$\mathrm{x}_{\mathrm{i}}^{\text {new }}=\mathrm{x}_{\mathrm{i}}^{\text {best }}+\mathrm{U}(-1,1) \times\left(\mathrm{x}_{\mathrm{ij}}-\mathrm{x}_{\mathrm{ik}}^{\text {best }}\right), i=1,2, \ldots, n$ and

$j \sim \mathrm{U}[1, \mathrm{HMS}]$,

$\mathrm{x}_{\mathrm{i}}^{\text {best }}$ is the $i^{\text {th }}$ component corresponding to the best solution vector resulted until the current iteration. $\mathrm{U}(-1,1)$ is a uniform random real number inside [$1,1]$ interval. In must be pointed out that, according to the above-mentioned changes, MHS algorithm has got only three parameters (HMS, PAR and $\mathrm{N}_{\max }$ ), while (HMCR and $\mathrm{bw}$ ) parameters are eliminated.

The MHS algorithm combines the HS algorithm with several features of $\mathrm{ABC}$ algorithm. Hybridizing HS algorithm with $\mathrm{ABC}$ algorithm has been done in other papers, too $[26,33]$, but this study has got some differences regarding the generating of a new harmony through memory consideration and pitch adjustment.

\section{Simulation Results and Comparison}

To test the efficiency of MHS algorithm two different test systems were studied: a 6-unit system, with power losses considered (test 
system 1), and a 38-unit system, without considering the power losses (test system 2). All case studies were implemented in MathCAD, on a personal computer having a $1.79 \mathrm{GHz}$ processor and $896 \mathrm{MB}$ of RAM. The solution's quality is evaluated through 100 or 200 trials.

For each trial the values of the following items are memorized: best total fuel cost $F$ (B), average total fuel cost $F$ (A), worst total fuel cost $F$ (W) and standard deviation (SD). For each system, values of the parameters used for HS and MHS algorithm (HMS, HMCR, PAR, bw, $\mathrm{N}_{\max }$ ) were determined by performing experimental trials.

\subsection{Test system 1: 6-unit with losses}

This case study contains a system of 6 units with transmission losses, ramp rate limits and prohibited operating zones of the units taken into consideration. The tested system data related to the cost coefficients $(a, b, c)$, power operating limits, ramp-rate limits, prohibited operating zones of the units, and also the loss coefficient $B$ are taken from $[6,34]$.

The load demand is $P_{D}=1263 \mathrm{MW}$. The characteristics of thermal power generating units and values of loss coefficient $B$ are described in Table 1 and Table 2.
For the studied system, after a few experimental trials, the parameters were set to the following values: $\mathrm{HMS}=8, \mathrm{PAR}=0.4$ and $\mathrm{N}_{\max }=1000$ (for the MHS algorithm) and $\mathrm{HMS}=8, \mathrm{HMCR}=0.9, \mathrm{PAR}=0.3, \mathrm{bw}=0.01$ and $\mathrm{N}_{\max }=1000$ [27] (for the HS algorithm).

Table 3 presents the output powers of thermal power generating units $\left(P_{i}, i=1,2, \ldots, 6\right)$ after running the MHS and HS algorithms. Values of B, A, W, SD items, generated power $\left(P_{G}\right)$, power losses $\left(P_{L}\right)$ and tolerance $(T O L)$ are also shown. Both algorithms satisfy the equality constraint (8) with a very high precision $\left(T O L_{\mathrm{MHS}}=-3.925 \cdot 10^{-13} \mathrm{MW}\right.$ and $T O L_{\mathrm{HS}}=-9.315 \cdot 10^{-11} \mathrm{MW}$ ).

T-test is applied for a comparison between the results obtained by MHS and HS algorithms.

Considering the characteristics of the MHS and HS algorithms shown in Table 3 - average (A) and standard deviation (SD) - the value of $t_{\text {calculated }}$ is computed $\left(t_{\text {calculated }}=3.113\right)$. Then, from the table with critical values "T-test", for a significance level of $1 \%, t_{\text {critical }}$ is returned $\left(t_{\text {critical }}=2.601\right)$. Since, $t_{\text {calculated }}=3.113>t_{\text {critical }}=2.601$, between the results obtained by MHS and HS algorithms there are significant statistical differences $\left(\mathrm{A}_{\mathrm{MHS}}<\mathrm{A}_{\mathrm{HS}}\right)$.

Table 1. The characteristics of thermal power generating units and prohibited operating zones (6-units)

\begin{tabular}{|c|c|c|c|c|c|c|c|c|c|}
\hline Unit & $\begin{array}{c}a \\
(\$ / \mathrm{h})\end{array}$ & $\begin{array}{c}b \\
(\$ / \mathrm{MWh})\end{array}$ & $\begin{array}{c}c \\
\left(\$ / \mathrm{MW}^{2} \mathrm{~h}\right)\end{array}$ & $\begin{array}{c}U R_{i} \\
(\mathrm{MW})\end{array}$ & $\begin{array}{c}D R_{\mathrm{i}} \\
(\mathrm{MW})\end{array}$ & $\begin{array}{c}P_{i}^{\text {Prev }} \\
(\mathrm{MW})\end{array}$ & $\begin{array}{c}P_{i, \min } \\
(\mathrm{MW})\end{array}$ & $\begin{array}{c}P_{i, \max } \\
(\mathrm{MW})\end{array}$ & Prohibited zone (MW) \\
\hline 1 & 240 & 7.0 & 0.0070 & 80 & 120 & 440 & 100 & 500 & {$[210240],[350380]$} \\
\hline 2 & 200 & 10.0 & 0.0095 & 50 & 90 & 170 & 50 & 200 & {$[90110],[140160]$} \\
\hline 3 & 220 & 8.5 & 0.0090 & 65 & 100 & 200 & 80 & 300 & {$[150170],[210240]$} \\
\hline 4 & 200 & 11.0 & 0.0090 & 50 & 90 & 150 & 50 & 150 & {$[8090],[110120]$} \\
\hline 5 & 220 & 10.5 & 0.0080 & 50 & 90 & 190 & 50 & 200 & {$[90110],[140150]$} \\
\hline 6 & 190 & 12 & 0.0075 & 50 & 90 & 110 & 50 & 120 & {$[7585],[100105]$} \\
\hline
\end{tabular}

Table 2. B-loss coefficient values (6-units)

\begin{tabular}{|c|c|c|c|c|c|c|}
\hline \multirow{6}{*}{$B_{i j}=$} & 17 & 12 & 7 & -1 & -5 & -2 \\
\hline & 12 & 14 & 9 & 1 & -6 & -1 \\
\hline & 7 & 9 & 31 & 0 & -10 & -6 \\
\hline & -1 & 1 & 0 & 24 & -6 & -8 \\
\hline & -5 & -6 & -10 & -6 & 129 & -2 \\
\hline & -2 & -1 & -6 & -8 & -2 & 150 \\
\hline $\mathrm{B}_{0 \mathrm{i}}=$ & -0.3908 & -0.1297 & 0.7047 & 0.0591 & 0.2161 & -0.6635 \\
\hline
\end{tabular}


Table 3. The best solution obtained using MHS and HS algorithms ( 6 units, $P_{D}=1263 \mathrm{MW}, 200$ trials)

\begin{tabular}{|c|c|c|}
\hline Output & MHS & HS \\
\hline $\mathrm{P}_{1}(\mathrm{MW})$ & 447.5038934324 & 447.5042986422 \\
\hline $\mathrm{P}_{2}(\mathrm{MW})$ & 173.3188266703 & 173.3204504696 \\
\hline $\mathrm{P}_{3}(\mathrm{MW})$ & 263.4628642464 & 263.462694264 \\
\hline $\mathrm{P}_{4}(\mathrm{MW})$ & 139.0649874081 & 139.0648289018 \\
\hline $\mathrm{P}_{5}(\mathrm{MW})$ & 165.4738752653 & 165.4731533959 \\
\hline $\mathrm{P}_{6}(\mathrm{MW})$ & 87.1338060426 & 87.1328232359 \\
\hline$P_{G}(M W)$ & 1275.9582530651 & 1275.9582489093 \\
\hline $\mathrm{P}_{\mathrm{L}}(\mathrm{MW})$ & 12.9582489093934 & 12.9582489093934 \\
\hline $\mathrm{P}_{\mathrm{D}}(\mathrm{MW})$ & 1263 & 1263 \\
\hline $\mathrm{TOL}_{\mathrm{M}}(\mathrm{MW})$ & $-3.925 \cdot 10^{-13}$ & $-9.315 \cdot 10^{-11}$ \\
\hline Best cost F (B) (\$/h) & 15449.8995248809 & 15449.8995249519 \\
\hline Average cost $\mathrm{F}(\mathrm{A})(\$ / \mathrm{h})$ & 15449.8995250435 & 15449.8995486667 \\
\hline Worst cost $\mathrm{F}(\mathrm{W})(\$ / \mathrm{h})$ & 15449.8995257499 & 15449.9007357696 \\
\hline SD (\$/h) & $1.7628 \cdot 10^{-7}$ & $1.0626 \cdot 10^{-4}$ \\
\hline
\end{tabular}

The convergence characteristics for MHS and HS algorithms are shown in Figure 1. It can be seen that both algorithms are able to reach the optimal solution, but MHS algorithm is faster; it needs a smaller number of iterations (approximately 130, while HS algorithm needs approx. 380 iterations).

MHS and HS algorithms robustness was studied by performing 200 trials. For each trial the best cost F (item B) was stored, and it was represented in Figure 2. In Figure 2 and Table 3 we note that MHS algorithm is very stable

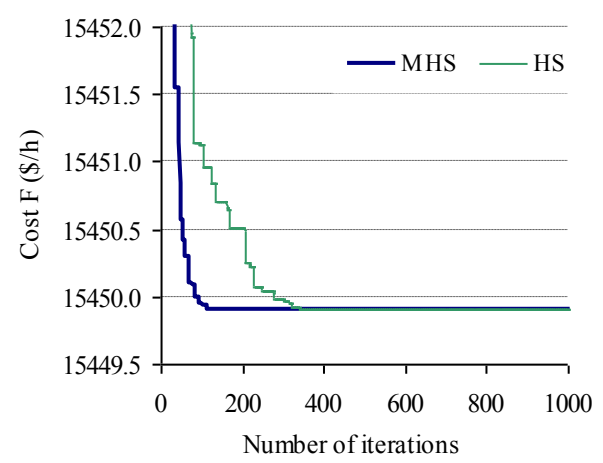

Figure 1. Convergence characteristics for MHS and HS algorithms, 6-units
Comparing MHS with other methods. When applying different optimization methods, results may be influenced by the level of satisfaction of the equality constraint (defined by (8) equation). Thus, all methods must be applied in similar conditions (tolerance value equation (17) - must be approximately the same for all methods).

$T O L_{M}=P_{G}-P_{L}-P_{D}$

In order to verify if MHS algorithm works in similar conditions like any other method $\mathrm{M}$, the

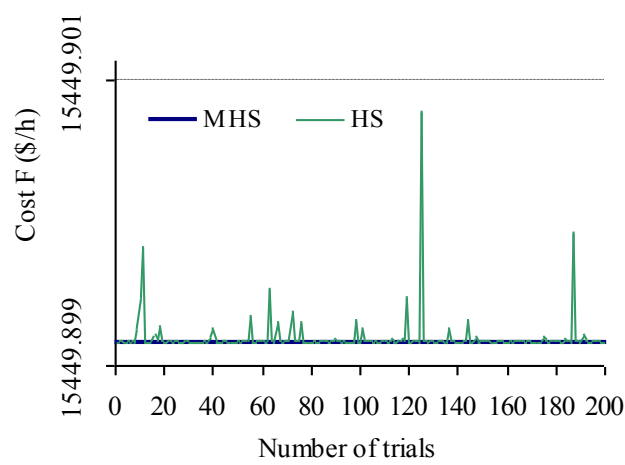

Figure 2. The best total cost $F$ obtained with MHS and HS algorithms, for 200 trials, 6-units
$\left(\mathrm{SD}_{\mathrm{MHS}}=1.7628 \cdot 10^{-7}<\mathrm{SD}_{\mathrm{HS}}=1.0626 \cdot 10^{-4}\right)$ and has the best items $\mathrm{B}_{\mathrm{MHS}}=15449.8995248 \$ \mathrm{~h} /$ $\mathrm{B}_{\mathrm{HS}}=15449.8995249 \$ / \mathrm{h}, \mathrm{A}_{\mathrm{MHS}}<\mathrm{A}_{\mathrm{HS}}$ and $\left.\mathrm{W}_{\mathrm{MHS}}<\mathrm{W}_{\mathrm{HS}}\right)$. following relation is used:

Dif_TOL $=\left|T O L_{\mathrm{MHS}}-T O L_{\mathrm{M}}\right|<\varepsilon$ 
where, $\mathrm{TOL}_{\mathrm{M}}, \mathrm{TOL}_{\mathrm{MHS}}$ is the tolerance for a method M, respectively algorithm MHS.

For the test system 1 , it is assumed that $\varepsilon=10^{-10}$ MW can be neglected, meaning that all methods are being applied in similar conditions with respect to satisfaction of equality constraint (8).

Table 4 shows a comparison between the results of MHS algorithm and three other optimization methods used for solving the same problem: particle swarm optimization (PSO) [6], multiple tabu search algorithm (MTS) [15] and differential evolution (DE) [16]. Thus, the set of methods $\mathrm{M}$ is: $\mathrm{M}=\{\mathrm{PSO}, \mathrm{DE}, \mathrm{MTS}\}$. It must be said that MHS algorithm was applied for similar conditions as the indicated methods were (for all comparisons: MHS vs. PSO, MHS then similar items obtained from PSO, DE and MTS algorithms.

Moreover, the worst value obtained by MHS algorithm is lower than the best value obtained by the methods specified (in Table 4 $W_{\mathrm{MHS}}<B_{\mathrm{PSO}}$ (MHS vs. PSO), $W_{\mathrm{MHS}}<B_{\mathrm{DE}}$ (MHS vs. DE) and $W_{\mathrm{MHS}}<B_{\mathrm{MTS}}$ (MHS vs. MTS)).

Values of items $B, A, W$ and $S D$ were calculated using a higher or, at least the same, number of trials like for the other methods (PSO, DE and MTS). The average computation time is of $5.4 \mathrm{sec}$.

From the items (B, A, W, SD) point of view, MHS algorithm proves to be superior comparing to HS, PSO, DE and MTS, as may be seen from

Table 4. Comparative results after applying different optimization techniques ( 6 units, $\left.P_{D}=1263 \mathrm{MW}\right)$.

\begin{tabular}{|c|c|c|c|c|c|c|}
\hline Method & PSO [6] & MHS & MTS [15] & MHS & $\mathrm{DE}[16]$ & MHS \\
\hline \multicolumn{7}{|c|}{ 1. Result described according to the indicated references } \\
\hline$P_{1}(\mathrm{MW})$ & 447.4970 & 447.5034920879 & 448.1277 & 447.5054236915 & 447.744 & 447.5016941993 \\
\hline$P_{2}(\mathrm{MW})$ & 173.3221 & 173.3168873323 & 172.8082 & 173.3179702901 & 173.407 & 173.3176508104 \\
\hline$P_{3}(\mathrm{MW})$ & 263.4745 & 263.462198913 & 262.5932 & 263.4634652066 & 263.411 & 263.4600979625 \\
\hline$P_{4}(\mathrm{MW})$ & 139.0594 & 139.065688249 & 136.9605 & 139.0657881467 & 139.076 & 139.0634606943 \\
\hline$P_{5}(\mathrm{MW})$ & 165.4761 & 165.4732611341 & 168.2031 & 165.4726437196 & 165.364 & 165.471156291 \\
\hline$P_{6}(\mathrm{MW})$ & 87.1280 & 87.1354007626 & 87.3304 & 87.1356138354 & 86.944 & 87.1327806056 \\
\hline Best $\operatorname{cost} F_{M}(\mathrm{~B})(\$ / \mathrm{h})$ & 15450 & 15449.8822209778 & 15450.06 & 15449.9350750959 & 15449.766 & 15449.7480804051 \\
\hline Average $F_{M}(\mathrm{~A})(\$ / \mathrm{h})$ & 15454 & 15449.8822211603 & 15451.17 & 15449.9350752945 & 15449.777 & 15449.7480806214 \\
\hline $\begin{array}{l}\text { Worst cost } F_{M} \\
(\mathrm{~W})(\$ / \mathrm{h})\end{array}$ & 15492 & 15449.8822220211 & 15453.64 & 15449.9350759751 & 15449.874 & 15449.7480816701 \\
\hline $\mathrm{SD}_{\mathrm{M}}(\$ / \mathrm{h})$ & - & $1.9053 \cdot 10^{-7}$ & 0.9287 & $1.9534 \cdot 10^{-7}$ & - & $2.3538 \cdot 10^{-7}$ \\
\hline Number of trials & 50 & 100 & 100 & 100 & 100 & 100 \\
\hline \multicolumn{7}{|c|}{$\begin{array}{l}\text { 2. The computation of the power loss }\left(P_{L}\right) \text {, generated power }\left(P_{G}\right) \text { and } T O L_{M} \text { tolerance based on the best solution described in the } \\
\text { indicated references }\end{array}$} \\
\hline$P_{G}(\mathrm{MW})$ & 1275.9571 & \begin{tabular}{|l|}
1275.9569284789 \\
\end{tabular} & 1276.0231 & 1275.9609048899 & 1275.9460 & 1275.9468405631 \\
\hline$P_{L}(\mathrm{MW})$ & 12.9583778743 & 12.95820635316 & 13.0204746591 & 12.95827954902 & 12.9571840155 & 12.95802457851 \\
\hline$T O L_{M}(\mathrm{MW})$ & -0.0012778743 & -0.00127787426 & 0.0026253408 & 0.002625340879 & -0.0111840155 & -0.01118401541 \\
\hline Dif_TOL* (MW) & 0 & $3.999 \cdot 10^{-11}$ & 0 & $7.899 \cdot 10^{-11}$ & 0 & $9.000 \cdot 10^{-11}$ \\
\hline
\end{tabular}

vs. DE and MHS vs. MTS, Table 4 indicates Dif_TOL $\left.<10^{-10} \mathrm{MW}\right)$.

Table 4 shows that MHS algorithm has got the best Cost $F$ (item $B$ ) for all the three analyzed situations: $B_{\mathrm{MHS}}=15449.882220 \$ / \mathrm{h}<B_{\mathrm{PSO}}=15450 \$ / \mathrm{h}$, $B_{\mathrm{MHS}}=15449.7480804 \$ / \mathrm{h}<B_{\mathrm{DE}}=15449.766 \$ / \mathrm{h}$, $\left.B_{\mathrm{MHS}}=15449.935075 \$ / \mathrm{h}<B_{\mathrm{MTS}}=15450.06 \$ / \mathrm{h}\right)$.

Also, items $A_{\mathrm{MHS}}, W_{\mathrm{MHS}}$ and $S D_{\mathrm{MHS}}$ obtained from MHS algorithm have got better values the results presented in Table 3 and Table 4 and the characteristics from Figure 1 and Figure 2.

\subsection{Test system 2: 38-unit without losses}

A 38-unit test system is studied in solving the ED problem with the MHS algorithm. The tested system data related to the cost coefficients $(a, b, c)$ and power operating limits are taken from [35]. The load demand is $P_{D}=6000 \mathrm{MW}$. 
For the system with 38-units, after a few experimental trials, the parameters used were set to the following values: $H M S=15, P A R=0.4$ and $N_{\max }=10000$ (for the MHS algorithm) and $\mathrm{HMS}=15, \mathrm{HMCR}=0.99, \mathrm{PAR}=0.3, \mathrm{bw}=10^{-6}$ and $\mathrm{N}_{\max }=10000$ (for the HS algorithm).

Table 5 shows the best solutions $\left(P_{i}, i=1,2, \ldots, 38\right)$ obtained from MHS and HS algorithms, as well as other solutions obtained from the following optimization technique PSO_TVAC [7],

Table 5. Best solution obtained using MHS and HS algorithms and comparison with other optimization techniques (38-units, $P_{D}=6000 \mathrm{MW}, 100$ trials)

\begin{tabular}{|c|c|c|c|c|c|}
\hline Output & MHS & $\mathrm{HS}$ & PSO_TVAC [7] & DE/BBO [36] & $\mathrm{BBO}[36]$ \\
\hline$P_{1}(\mathrm{MW})$ & 426.6055451709 & 426.600231683 & 443.659 & 426.606060 & 422.230586 \\
\hline$P_{2}(\mathrm{MW})$ & 426.6047089764 & 426.5937015757 & 342.956 & 426.606054 & 422.117933 \\
\hline$P_{3}(\mathrm{MW})$ & 429.6635302444 & 429.650913618 & 433.117 & 429.663164 & 435.779411 \\
\hline$P_{4}(\mathrm{MW})$ & 429.6647862209 & 429.675753655 & 500.000 & 429.663181 & 445.481950 \\
\hline$P_{5}(\mathrm{MW})$ & 429.6667821468 & 429.6545940263 & 410.539 & 429.663193 & 428.475752 \\
\hline$P_{6}(\mathrm{MW})$ & 429.6628268036 & 429.6702425681 & 482.864 & 429.663164 & 428.649254 \\
\hline$P_{7}(\mathrm{MW})$ & 429.6609836262 & 429.6691319879 & 409.483 & 429.663185 & 428.119288 \\
\hline$P_{8}(\mathrm{MW})$ & 429.6631083527 & 429.6689470513 & 446.079 & 429.663168 & 429.900663 \\
\hline$P_{9}(\mathrm{MW})$ & 114.0000000000 & 114.000001626 & 119.566 & 114.000000 & 115.904947 \\
\hline$P_{10}(\mathrm{MW})$ & 114.0000000000 & 114.0000000000 & 137.274 & 114.000000 & 114.115368 \\
\hline$P_{11}(\mathrm{MW})$ & 119.7673921028 & 119.7662422478 & 138.933 & 119.768032 & 115.418662 \\
\hline$P_{12}(\mathrm{MW})$ & 127.0724320711 & 127.076361834 & 155.401 & 127.072817 & 127.511404 \\
\hline$P_{13}$ (MW) & 110.0000000000 & 110.0000000000 & 121.719 & 110.000000 & 110.000948 \\
\hline$P_{14}(\mathrm{MW})$ & 90.0000000000 & 90.0000000000 & 90.924 & 90.0000000 & 90.0217671 \\
\hline$P_{15}(\mathrm{MW})$ & 82.0000000003 & 82.0000000000 & 97.941 & 82.0000000 & 82.0000000 \\
\hline$P_{16}$ (MW) & 120.0000000000 & 120.0000000000 & 128.106 & 120.000000 & 120.038496 \\
\hline$P_{17}(\mathrm{MW})$ & 159.5982110232 & 159.599299215 & 189.108 & 159.598036 & 160.303835 \\
\hline$P_{18}(\mathrm{MW})$ & 65.0000000000 & 65.0000000000 & 65.000 & 65.0000000 & 65.0001141 \\
\hline$P_{19}(\mathrm{MW})$ & 65.0000000000 & 65.0000000000 & 65.000 & 65.0000000 & 65.0001370 \\
\hline$P_{20}(\mathrm{MW})$ & 272.0000000000 & 272.0000000000 & 267.422 & 272.000000 & 271.999591 \\
\hline$P_{21}(\mathrm{MW})$ & 272.0000000000 & 272.0000000000 & 221.383 & 272.000000 & 271.872680 \\
\hline$P_{22}(\mathrm{MW})$ & 260.0000000000 & 259.99999997967 & 130.804 & 260.000000 & 259.732054 \\
\hline$P_{23}(\mathrm{MW})$ & 130.6483891957 & 130.6460481007 & 124.269 & 130.648618 & 125.993076 \\
\hline$P_{24}(\mathrm{MW})$ & 10.0000000000 & 10.0000006793 & 11.535 & 10.0000000 & 10.4134771 \\
\hline$P_{25}(\mathrm{MW})$ & 113.3051024999 & 113.3130828089 & 77.103 & 113.305034 & 109.417723 \\
\hline$P_{26}(\mathrm{MW})$ & 88.0671008506 & 88.0692392482 & 55.018 & 88.0669159 & 89.3772664 \\
\hline$P_{27}(\mathrm{MW})$ & 37.5056685997 & 37.5059577346 & 75.000 & 37.5051018 & 36.4110655 \\
\hline$P_{28}(\mathrm{MW})$ & 20.0000000000 & 20.0000000000 & 21.682 & 20.0000000 & 20.0098880 \\
\hline$P_{29}(\mathrm{MW})$ & 20.0000000000 & 20.0000000000 & 29.829 & 20.0000000 & 20.0089554 \\
\hline$P_{30}(\mathrm{MW})$ & 20.0000000000 & 20.0000000000 & 20.326 & 20.0000000 & 20.0000000 \\
\hline$P_{31}(\mathrm{MW})$ & 20.0000000000 & 20.0000000000 & 20.000 & 20.0000000 & 20.0000000 \\
\hline$P_{32}(\mathrm{MW})$ & 20.0000000000 & 20.0000000000 & 21.840 & 20.0000000 & 20.0033959 \\
\hline$P_{33}(\mathrm{MW})$ & 25.0000000000 & 25.0000000000 & 25.620 & 25.0000000 & 25.0066586 \\
\hline$P_{34}(\mathrm{MW})$ & 18.0000000000 & 18.0000000000 & 24.261 & 18.0000000 & 18.0222107 \\
\hline$P_{35}(\mathrm{MW})$ & 8.0000000000 & 8.0000000000 & 9.667 & 8.00000000 & 8.00004260 \\
\hline$P_{36}(\mathrm{MW})$ & 25.0000000000 & 25.0000000000 & 25.000 & 25.0000000 & 25.0060660 \\
\hline$P_{37}(\mathrm{MW})$ & 21.7817319076 & 21.7811436951 & 31.642 & 21.7820891 & 22.0005641 \\
\hline$P_{38}(\mathrm{MW})$ & 21.0616992228 & 21.0591058638 & 29.935 & 21.0621792 & 20.6076309 \\
\hline $\mathrm{P}_{\mathrm{G}}(\mathrm{MW})$ & 5999.9999990156 & 5999.9999990154 & 6000.005 & 5999.999992 & 5999.95286 \\
\hline $\mathrm{P}_{\mathrm{D}}(\mathrm{MW})$ & 6000 & 6000 & 6000 & 6000 & 6000 \\
\hline $\mathrm{TOL}_{\mathrm{M}}(\mathrm{MW})$ & $-9.844 \cdot 10^{-7}$ & $-9.846 \cdot 10^{-7}$ & $5.000 \cdot 10^{-3}$ & $-8.000 \cdot 10^{-6}$ & $-4.713 \cdot 10^{-2}$ \\
\hline Best cost $F_{M}(\$ / \mathrm{h})$ & 9417235.78535618 & 9417235.78581085 & 9500448.307 & 9417235.786391673 & 9417633.63764437 \\
\hline Average $F_{M}(\$ / \mathrm{h})$ & 9417235.78606311 & 9417235.78707343 & - & - & - \\
\hline Worst cost $F_{M}(\$ / \mathrm{h})$ & 9417235.78641317 & 9417235.79132093 & - & - & - \\
\hline $\mathrm{SD}_{\mathrm{M}}(\mathrm{S} / \mathrm{h})$ & $3.852 \cdot 10^{-4}$ & $8.196 \cdot 10^{-4}$ & - & - & - \\
\hline
\end{tabular}

“-” data not available 
Biogeography-Based Optimization (BBO) [36], Hybrid Differential Evolution with BiogeographyBased Optimization (DE/BBO) [36]. Therefore, the set of methods $\mathrm{M}$ consists of: $\mathrm{M}=\{\mathrm{PSO}$ TVAC, $\mathrm{BBO}, \mathrm{DE} / \mathrm{BBO}\}$. At the end of Table 5 items $B, A$, $W$ and $S D$ are shown for all methods.

The values $t_{\text {calculed }}$ and $t_{\text {critical }}$, for a significance level of $1 \%$, were determined by applying "Ttest". Since, $t_{\text {calculated }}=11.44>t_{\text {critical }}=2.626$, between the results obtained by MHS and HS algorithms there are significant statistical differences $\left(\mathrm{A}_{\mathrm{MHS}}<\mathrm{A}_{\mathrm{HS}}\right)$. Convergence characteristics for MHS and HS algorithms (for 38-units) are shown in Figure 3.

It is observed that MHS has a better convergence than HS algorithm. In Fig. 4 the best values of Cost $F$ (B) function for MHS and HS algorithms are depicted (considering 100 trials). The data from Table 5 and Figure 4 show that MHS algorithm has a better stability than the HS algorithm $\left(S D_{\mathrm{MHS}}=3.852 \cdot 10^{-4}\right.$ $\left.<S D_{\mathrm{HS}}=8.196 \cdot 10^{-4}\right)$. Also, the values of items $\mathrm{B}$, $\mathrm{A}, \mathrm{W}$ and SD are better in case of MHS algorithm, comparing to the values of similar items obtained by HS algorithm (Table 5). The average computation time is of $47.2 \mathrm{sec}$.

Comparing MHS with other methods. Analyzing Table 5 and focusing on item $B$, it can be seen that MHS algorithm is superior comparing to other optimization methods: PSO TVAC, BBO. The worst value obtained by MHS algorithm is better than the best value obtained by PSO_TVAC ( $W_{\text {MHS }}<B_{\text {PSO }}$ TVAC $)$ and $\mathrm{BBO}\left(W_{\mathrm{MHS}}<B_{\mathrm{BBO}}\right)$. Also, MHS algorithm has better results than HS algorithm $\left(B_{\mathrm{MHS}}<B_{\mathrm{DE} / \mathrm{BBO}}\right)$, when equality constraint (8) is satisfied with a higher precision:

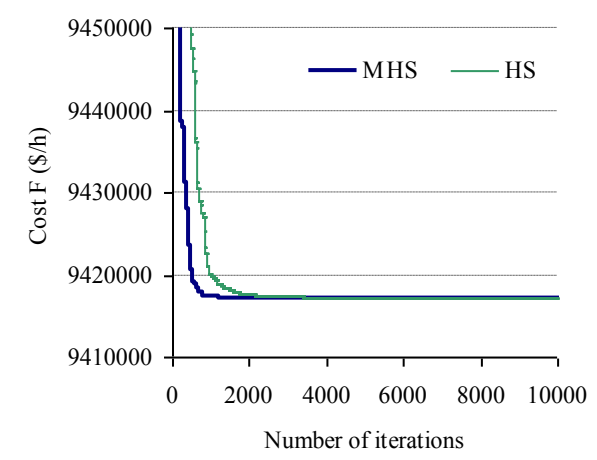

Figure 3. Convergence characteristics for MHS and HS algorithms, 38-units
$\left(\left|T O L_{\mathrm{MHS}}\right|=9.844 \cdot 10^{-7}<\left|T_{\mathrm{DE} / \mathrm{BBO}}\right|=8.000 \cdot 10^{-6}\right)$.

\section{CONCLUSION}

In this paper, the MHS algorithm has been tested to solve the economic dispatch problem. The MHS algorithm is based on harmony search algorithm. Some features of HS algorithm were replaced with others belonging to artificial bee colony algorithm, in order to enhance its capacity to avoid premature convergence and to get high-quality solutions.

To solve a 6-units test system, several operational characteristics of thermal power generating units were considered (ramp-rate limits, prohibited operating zones, minimum and maximum power operating limits) that define a range of non-continuous values for the output powers of thermal power generating units. Transmission losses in electric line were also considered.

The MHS algorithm was successfully applied on two test systems consisting of 6 units and 38 units. Results show that MHS algorithm is better than HS algorithm for both case studied, if considering items $\mathrm{B}, \mathrm{A}, \mathrm{W}$ and $\mathrm{SD}$. Also, MHS algorithm is better than other optimization techniques used for solving this problem (PSO, DE and MTS for 6-units), respective ( $\mathrm{PSO}$-TVAC, $\mathrm{DE} / \mathrm{BBO}$ and $\mathrm{BBO}$ for 38-units). Considering these good results, it may be said that MHS algorithm has the ability to obtain high-quality solutions, guarantees stability and a good calculation time, both for the 6-units test system, and for the large-scale test system with 38-units.

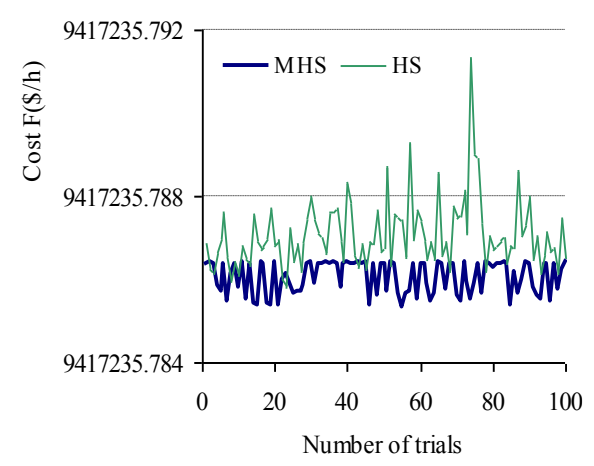

Figure 4. The best total cost $F$ obtained with MHS and HS algorithms, for 100 trials, 38-units 


\section{REFERENCES}

1. PARIKH, J., D. CHATTOPADHYAY, A Multi-Area Linear Programming Approach for Analysis of Economic Operation of the Indian Power System, IEEE Transaction on Power System, vol. 11(1), 1996, pp. 52-58.

2. NANDA, J., L. HARI, M. L. KOTHARI, Economic Emission Load Dispatch with Line Flow Constraints Using a Classical Technique. IEE Proceedings Generation, Transmission and Distribution, Vol. 141(1), 1994, pp. 1-10.

3. PAPAgEORGIOU, L., E. FRAGA, A Mixed Integer Quadratic Programming Formulation for the Economic Dispatch of Generators with Prohibited Operating Zones. Electric Power System Research, Vol. 77(10), 2007, pp. 1292-1296.

4. BARD, J. F., Short-term Scheduling of Thermal-Electric Generators using Lagrangian Relaxation, Operations Research, Vol. 36(5), 1988, pp. 756-766.

5. TRAVERS, D., R. KAYE, Dynamic Dispatch by Constructive Dynamic Programming. IEEE Transaction on Power System, Vol. 13(1), 1998. pp. 72-78.

6. GAING, Z.-L., Particle Swarm Optimization to Solving the Economic Dispatch Considering the Generator Constraints, IEEE Transaction on Power System, Vol. 18(3), 2003, pp. 1187-1195.

7. CHATURVEDI, K. T., M. PANDIT, L. SRIVASTAVA, Particle Swarm Optimization with Time Varying Acceleration Coefficients for NonConvex Economic Power Dispatch, Electrical Power and Energy Systems, Vol. 31(6), 2009, pp. 249-257.

8. SECUI, D. C., I. FELEA, S. DZITAC, L. POPPER, A Swarm Intelligence Approach to the Power Dispatch Problem, International Journal of Computers Communications \& Control, Vol. 5(3), 2010, pp. 375-384.

9. SELVAKUMAR, A. I., K. THANUSHKODI, A New Particle Swarm Optimization Solution to Non-Convex Economic Dispatch Problems, IEEE Transaction on Power System, Vol. 22(1), 2007, pp. 42-51.
10. NIKNAM, T., H. D. MOJARRAD, H. Z. MEYMAND, A New Particle Swarm Optimization for Non-Convex Economic Dispatch, European Transactions on Electrical Power, Vol. 21(1), 2011, pp. 656-679.

11. PARK, J.-B., Y.-W. JEONG, J.-R. SHIN, K. Y. LEE, An Improved Particle Swarm Optimization for Non-Convex Economic Dispatch Problems, IEEE Transaction on Power System, Vol. 25(1), 2010, pp. 155-166.

12. KHAMSAWANG, S., S. JIRIWIBHAKORN, DSPSO-TSA for Economic Dispatch Problem with NonSmooth and Non-continuous Cost Functions. Energy Conversion and Management, Vol. 51(2), 2010, pp. 365-75.

13. SINHA, N., R. CHAKRABARTI, P. K. CHATTOPADHYAY, Evolutionary Programming Techniques for Economic Load Dispatch, IEEE Transactions on Evolutionary Computation, Vol. 7(1), 2003, pp. 83-94.

14. BHATTACHARYA, A., P. K. CHATTOPADHYAY, Biogeography-based Optimization for Different Economic Load Dispatch Problems, Power Systems, Vol. 25(2), 2010, pp. 1064-1077.

15. POTHIYA, S., I. NGAMROO, W. KONGPRAWECHNON, Application of Multiple Tabu Search Algorithm to Solve Dynamic Economic Dispatch Considering Generator Constraints, Energy Conversion and Management, Vol. 49(4), 2008, pp. 506-516.

16. NOMAN, N., H. IBA, Differential Evolution for Economic Load Dispatch Problems, Electric Power System Research, Vol. 78(3), 2008, pp. 1322-1331.

17. PEREZ-GUERRERO, R. E. J. R. CEDENIO-MALDONADO, Economic Power Dispatch with Non-smooth Cost Functions using Differential Evolution, Proceedings of the 37th Annual North American, Power Symposium, Ames, Iowa, 2005, pp. 183-190.

18. SAYAH, S., A. HAMOUDA, A Hybrid Differential Evolution Algorithm based on Particle Swarm Optimization for Non-convex Economic Dispatch Problems, Applied Soft Computing, Vol. 13(4), 2013, pp. 1608-1619. 
19. HEMAMALINI, S., S. P. SIMON, Artificial Bee Colony Algorithm for Economic Load Dispatch Problem with Non-smooth Cost Functions, Electric Power Components and Systems, Vol. 38(7), 2010, pp. 786-803.

20. ÖZYÖN, S. D. AYDIN, Incremental Artificial Bee Colony with Local Search to Economic Dispatch Problem with Ramp Rate Limits and Prohibited Operating Zones, Energy Conversion and Management, Vol. 65, 2013, pp. 397-407.

21. ARUL, R., G. RAVI, S. VELUSAMI, Non-Convex Economic Dispatch with Heuristic Load Patterns, Valve Point Loading Effect, Prohibited Operating Zones, Ramp-Rate Limits and Spinning Reserve Constraints using Harmony Search Algorithm, Electrical Engineering, Vol. 95(1), 2012, pp. 53-61.

22. WANG, L., L.-P. LI, An Effective Differential Harmony Search Algorithm for the Solving Non-Convex Economic Load Dispatch Problems, Electrical Power and Energy Systems, Vol. 44(1), 2013, pp. 832-843.

23. GEEM, Z. W., J. H. KIM, G. V. LOGANATHAN, A New Heuristic Optimization Algorithm: Harmony Search, Simulation, vol. 76(2), 2001, pp. 60-68.

24. LEE, K. S., Z. W. GEEM, A New MetaHeuristic Algorithm for Continuous Engineering Optimization: Harmony Search Theory and Practice, Computer methods in applied mechanics and engineering, Vol. 194(36-38), 2005, pp. 3902-3933.

25. ZOU, D., L. GAO, J. WU, S. LI, Novel Global Harmony Search Algorithm for Unconstrained Problems, Neurocomputing, Vol. 73(16-18), 2010, pp. 3308-3318.

26. WU, B., C. QIAN, W. NI, S. FAN, Hybrid Harmony Search and Artificial Bee Colony Algorithm for Global Optimization Problems, Computers and Mathematics with Applications, Vol. 64(8), 2012, pp. 2621-2634.

27. OMRAN, M. G. H. M. MAHDAVI, Global-Best Harmony Search, Applied Mathematics and Computation, Vol. 198(2), 2008, pp. 643-656.
28. ZOU, D., L. GAO, S. LI, J. WU, An Effective Global Harmony Search Algorithm for Reliability Problems, Expert Systems with Applications, Vol. 38(4), 2011, pp. 4642-4648.

29. VERA-PEREZ, O. L., A. MESEJOCHIONG, A. JAUME-I-CAPO, M. GONZALEZ-HIDALGO, Automatic Parameter Configuration: A Case Study on a Rehabilitation Oriented Human Limb Tracking Algorithm, Studies in Informatics and Control, vol. 23 (1), 2014, pp. 87-96.

30. GEEM, Z. W., Optimal Cost Design of Water Distribution Networks using Harmony Search, Eng. Optimization, Vol. 38(3). 2006, pp. 259-280.

31. KARABOGA, D. B. BASTURK, A Powerful and Efficient Algorithm for Numerical Function Optimization: Artificial Bee Colony (ABC) Algorithm, Journal of Global Optimization, Vol. 39(3), 2007, pp. 459-471.

32. AKAY, B., D. KARABOGA, A Modified Artificial Bee Colony Algorithm for Real-Parameter Optimization, Information Sciences, Vol. 192(1), 2012, pp. 120-142.

33. KRISHNAVENI, V., G. ARUMUGAM, A Novel Enhanced Bio-Inspired Harmony Search Algorithm for Clustering, Proceedings of the International Conference Recent Advances in Computing and Software Systems (RACSS), Chennai, 2012, pp. 7-12.

34. GAING, Z.-L., Closure to Discussion of Particle Swarm Optimization to Solving the Economic Dispatch Considering the Generator Constraints. IEEE Tr. on Power Systems, Vol. 19(4), 2004, pp. 2122-2123.

35. SYDULU, M., A Very Fast and Effective Non-Iterative Lamda Logic based Algorithm for Economic Dispatch of Thermal Units, Proceedings of the IEEE Region 10 Conference TENCON, Cheju Island, Vol. 2, 1999, pp. 1434-1437.

36. BHATTACHARYA, A., P. K. CHATTOPADHYAY, Hybrid Differential Evolution with Biogeography-based Optimization for Solution of Economic Load Dispatch, IEEE Trans. on Power Systems, Vol. 25(4), 2010, pp. 1955-1964. 